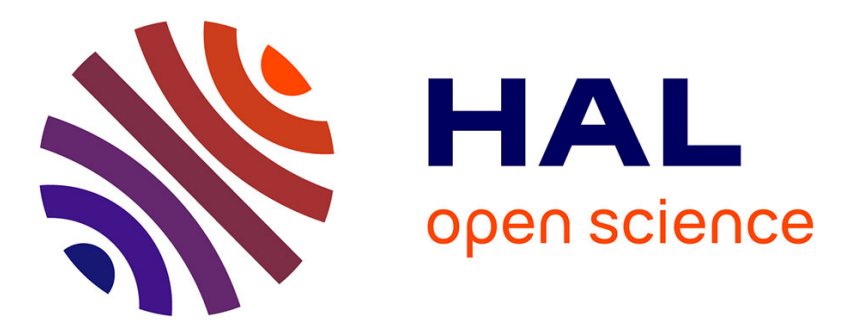

\title{
CityScope Hanoi: interactive simulation for water management in the Bac Hung Hai irrigation system
}

Arnaud Grignard, Tri Nguyen-Huu, Benoit Gaudou, Doanh Nguyen-Ngoc, Arthur Brugière, Tu Dang-Huu, Huynh Quang Nghi, Nguyen Trong Khanh, Kent Larson

\section{To cite this version:}

Arnaud Grignard, Tri Nguyen-Huu, Benoit Gaudou, Doanh Nguyen-Ngoc, Arthur Brugière, et al.. CityScope Hanoi: interactive simulation for water management in the Bac Hung Hai irrigation system. 12th International Conference on Knowledge and Systems Engineering (KSE 2020), Nov 2020, Can Tho city, Vietnam. pp.153-158, 10.1109/KSE50997.2020.9287831 . hal-03086988

\section{HAL Id: hal-03086988 https://hal.science/hal-03086988}

Submitted on 5 Jan 2021

HAL is a multi-disciplinary open access archive for the deposit and dissemination of scientific research documents, whether they are published or not. The documents may come from teaching and research institutions in France or abroad, or from public or private research centers.
L'archive ouverte pluridisciplinaire HAL, est destinée au dépôt et à la diffusion de documents scientifiques de niveau recherche, publiés ou non, émanant des établissements d'enseignement et de recherche français ou étrangers, des laboratoires publics ou privés. 


\section{CityScope Hanoi: interactive simulation for water management in the Bac Hung Hai irrigation system}

\author{
Arnaud Grignard \\ City Science \\ MIT Media Lab \\ Cambridge, USA \\ agrignard@media.mit.edu
}

\author{
Tri Nguyen-Huu \\ Sorbonne Université, IRD, UMMISCO \\ JEAI WARM, UMMISCO/SU/IRD and TLU \\ Bondy, France \\ tri.nguyen-huu@ird.fr
}

\author{
Benoit Gaudou \\ IRIT, Univ. Toulouse Capitole \\ UMMISCO, SU and IRD \\ ICTLab, USTH \\ Hanoi, Vietnam \\ benoit.gaudou@gmail.com
}

\author{
Doanh Nguyen-Ngoc \\ Thuyloi University \\ JEAI WARM, UMMISCO/SU/IRD and TLU \\ Hanoi, Vietnam \\ doanhnn@tlu.edu.vn
}

\author{
Arthur Brugière \\ ICTLAb, USTH \\ UMMISCO, SU and IRD \\ Hanoi, Vietnam \\ contact@arthurbrugiere.fr
}

\author{
Tu Dang-Huu \\ ICTLab, USTH \\ JEAI WARM, UMMISCO/SU/IRD and TLU \\ Hanoi, Vietnam \\ tudh.hust@gmail.com
}

\author{
Huynh Quang Nghi \\ Can Tho University \\ UMMISCO, SU and IRD \\ Can Tho, Vietnam \\ hqnghi@ctu.edu.vn
}

\author{
Nguyen Trong Khanh \\ PTIT University \\ JEAI WARM, UMMISCO/SU/IRD and TLU \\ Hanoi, Vietnam \\ khanhnt82@gmail.com
}

\author{
Kent Larson \\ City Science \\ MIT Media Lab \\ Cambridge, USA \\ kll@media.mit.edu
}

\begin{abstract}
Irrigation systems contribute worldwide to the provision of a wide range of services on which the survival and well-being of humanity depend. They are of primary importance in Vietnam where about $90 \%$ of the water used is for irrigation and aquaculture and where agriculture is the largest employer and a major contributor to the national GDP and to the income of the low-salary households. Nevertheless, irrigation systems have recently been subjected to several issues including increasing demand, pollution, under-investment, depletion of resources or environmental changes. Any mitigation measure against these issues needs to be sustainable with respect to the very diverse uses of the water, the changing conditions upstream and downstream, and the somewhat conflicting objectives carried out by landuse/agricultural planning on one hand and urbanization and society well-being on the other. This need of sustainability requires the design of innovative tools to tackle these issues. This work aims at exploring the usage of Agent-Based Modelling coupled with a tangible and interactive interface in order to enhance interactions between stakeholders and support the evaluation of various alternatives of the management of the Bac Hung Hai irrigation system.
\end{abstract}

Index Terms-Agent-Based Model, CityScope, GAMA platform, interactive simulation, Bac Hung Hai, irrigation system

\section{INTRODUCTION}

Irrigation systems contribute worldwide to the provision of a wide range of services on which the survival and well-being of humanity depends. They are of primary importance in Vietnam where about $90 \%$ of the water used is for irrigation and aquaculture $^{1}$ and where agriculture is the largest employer and a major contributor to the national GDP and to the income of the low-salary households. Nevertheless, irrigation systems have recently been subjected to several issues including increasing demand, pollution, under-investment, depletion of sources or environmental changes. Climate change is impacting water availability and increasing peak rainfall but also increasing the intensity of droughts [1]. As an example, the Bac Hung Hai irrigation system, which lies in the Red River Delta, is currently heavily affected by environmental pollution, with hundreds of sewers flowing into the river. With a large area crossing four provinces, it constitutes an irrigation canal for hundreds of thousand hectares of agricultural land, but the pollution caused for many years by Bac Hung Hai irrigation system seriously affects the life, activities, and production of millions of inhabitants.

Any mitigation measure against these issues needs to be sustainable with respect to the very diverse uses of the water, the changing conditions upstream and downstream, and the somewhat conflicting objectives carried out by land-use/agricultural

\footnotetext{
${ }^{1}$ more than $94 \%$ in 2005 for agriculture and livestock. Source: https://data. worldbank.org/indicator/ER.H2O.FWAG.ZS?locations=VN.
} 
planning on one hand and urbanization and society wellbeing on the other hand. Any management solution of the irrigation system should thus not only be assessed considering the system as a simple physical set of channels and gates transporting water, but rather as a whole socio-environmental system. This induces the need of innovative tools to support decisions and consultation, able to integrate all the social, environmental and economic aspects of the system in a single object, that can be the object of experiments to answer whatif (such management policy is applied) and how-to (reach a sustainable state related to such indicators) questions and can favour participation and interactions between the various stakeholders, decision-makers and users.

In this context, Agent-Based Modelling (ABM) appears as an invaluable leverage. ABM is based on the design of models representing the behaviour of a system as an emerging feature of computational entities (agents) in interaction in a simulated environment [2], [3]. This approach has become the approach of choice to represent socio-environmental systems (such as irrigation systems [4], [5]), especially when they require the inputs of different disciplines to be designed. This approach is also well-adapted to design participatory simulations, where human beings can control an artefact agent in the simulation [6], [7].

This CityScope Hanoi project aims at exploring the usage of Agent-Based Modelling coupled with a tangible and interactive interface in order to ease the decision-making process of the management of an irrigation system, facing mainly issues of pollution and water scarcity. The full setup will be based on an Agent-Based Model $^{2}$ developed using the GAMA Platform [8] to represent the water flow, the various land use evolution and the pollution emitted in the system. This model will be integrated in the CityScope framework [9]. The chosen case study is the Bac Hung Hai irrigation system close to Hanoi, in the Red River Delta, Vietnam.

The paper is organized as follows. Section II will first present the Bac Hung Hai irrigation system. Section III will present some related works. The Agent-Based Model is presented in Section IV and the interactive table in Section V. Section VI summarizes the preliminary results. Finally, Section VII concludes the paper and discusses some perspectives.

\section{CASE STUDY}

The Bac Hung Hai irrigation system lies in the centre of the Red River Delta. Its North-West area covers a part of Hanoi city. It is bounded by four rivers: Duong river (North, $67 \mathrm{~km}$ ), Luoc river (South, $72 \mathrm{~km}$ ), Thai Binh river (East, 73 $\mathrm{km}$ ), and the Red river (West, $57 \mathrm{~km}$ ) (cf. Fig. 1). Its area is 214.932 ha: 192.045 ha inside dykes and 22.887 ha outside. It plays an important role in the economic development of the region by: (1) providing irrigation to 110.000 ha of rice, crop and tree lands; (2) bringing water for livestock, poultry, and aquaculture (12.000 ha); (3) providing water for

\footnotetext{
${ }^{2}$ The model is distributed as an open-source software. It is available on its GitHub repository https://github.com/CityScope/CSL_Hanoi.
}

more than three million people and industrial zones $(4.300$ ha); (4) controlling flooding inside the dyke area to protect people's livelihoods and agricultural production. According to the report of Bac Hung Hai Company in July 2019, water pollution in the system is one of the main issues identified by managers, users and stakeholders.

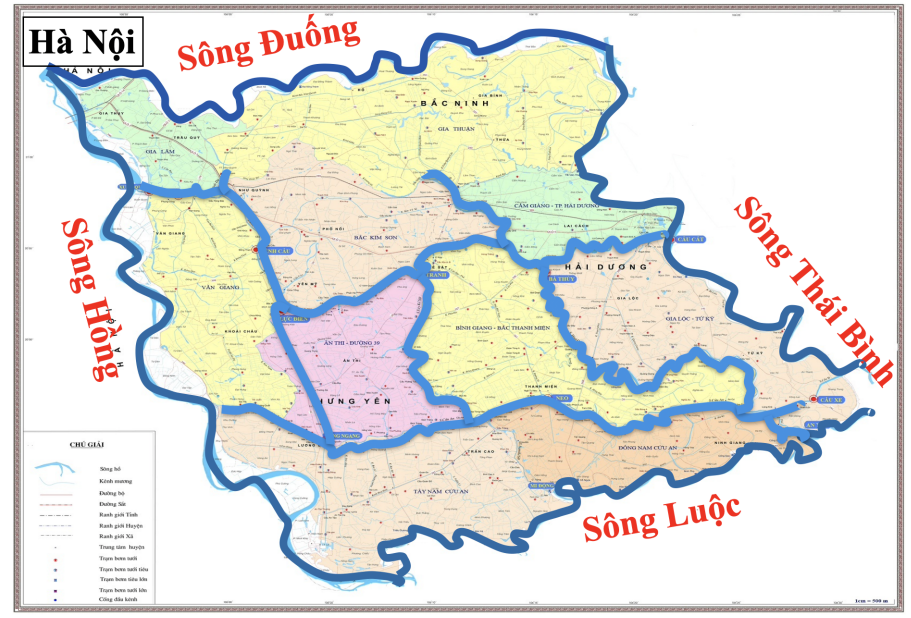

Fig. 1. Map of the Bac Hung Hai irrigation system.

\section{STATE OF THE ART}

\section{A. Hydrology modelling}

The Bac Hung Hai irrigation system is located in the Red River delta. Modelling the water flow in delta areas is not an easy task, as the slope is almost zero (preventing the use of models at the scale of the basin, such as SWAT in [4]). Even the direction of the flow can depend on the sea tide, or the season. This explains the very low number of works about the water flow modelling in this irrigation system. The only one we are aware of is a modelling using the Mike $11^{3}$ software [10]. This approach is able to provide good results when calibrated with real data. Nevertheless, it cannot be used in an interactive mode, with users changing the river network (by opening and closing a gate for example) or the withdrawal processes (by modifying the land use).

We thus decided to implement an ad hoc model in GAMA which should fulfil our two main constraints: (i) it can adapt to any change in the river network, (ii) it allows to visualize easily quantitative and qualitative results. We have decided to not implement a model of water flow in river sections similar to Mike 11's one, as it is not easy to visualize both the quantity and quality of water in river sections (increasing the size of the river when the flow is huge is not really easy to perceive on an interactive table). So we develop a much less precise model, based on discrete water elements moving on the network. It allows us to display the quantity with the number of water agent and the quality with different colours.

\footnotetext{
${ }^{3}$ Mike 11 website: https://www.mikepoweredbydhi.com/products/mike-11.
} 


\section{B. Interactive simulation}

The key idea of interactive and tangible simulations is to use a tangible support to display the simulation (sandbox, 3D printed map...) and to allow users to interact with it in an intuitive manner. First examples were mainly dedicated to landscape modelling and evolution [11]. Several studies have shown the benefits of such tangible objects to help the user to think spatial information and dynamics (see Chapter 1 of [11]), improving thus the learning and understanding processes [12].

First Agent-Based Models linked to a tangible interface were mainly dedicated to urban simulations such as [13]. Later the CityScience research group (of the MIT Media Lab) has developed several projects [9], [14] to give the possibility to visualize the link between urban planning and organization, mobility modes and traffic. [15], [16] focus on the link between traffic (in particular related to vehicle numbers and states) and air pollution.

CityScope Hanoi is thus an instance of the CityScope framework, but applied for the first time to an environmental case study, including water flow, water pollution, land use water withdrawal and pollution emission.

\section{MOdel}

We present in this section the key elements of the CityScope Hanoi model, developed using the agent-based modelling and simulation platform GAMA [8], providing only the key parts of the standard O.D.D. (Overview, Design concepts, Details) protocol [17].

\section{A. Overview of the model}

The model aims at exploring the combined impacts of various land use organization and water management on the water quantity and quality in the Bac Hung Hai irrigation system. The main question tackled by the model is: how to reach a sustainable state of the Bac Hung Hai irrigation system that fulfil the needs and well-being of the human population?

\section{B. Description of the model entities}

The model is composed of three main parts: the hydrological sub-model, the land use sub-model and the pollution submodel, which are deeply interconnected. The main entities and their links are summarized in Fig. 2.

In this project, we have decided to implement a discrete water flow model to improve the simulation visualization: the water is represented by a set of individual water agents moving on a network of river agents. The water "mobility" is impacted by a set of gate agents located at the intersection of rivers. These gate agents can be either opened or closed (allowing or preventing the water flow) and they can be source (resp. sink) and create (resp. take out) water agents for the river network.

The land use sub-model manages the 2 types of entities related to the land use and its evolution: landuse and cell agents. Each of them is characterized by a land use type attribute. Among the 2 entities, cell agents manage the link with the rivers. They withdraw water and create pollution. In addition, cell agents type is set by data coming from the user (through the scanner, see section below). landuse agents are mainly used for display purpose and to manage dryness.

The pollution sub-model is based on a collection of pollutants agents for every agriculture's elements: static_pollution, which represent land pollution, and polluted_water, for water. Each static_pollution is generated from polluted_water (in an area of $4 \mathrm{~km}$ ) in order to reduce the water pollution and negatively impact the landuse agents.

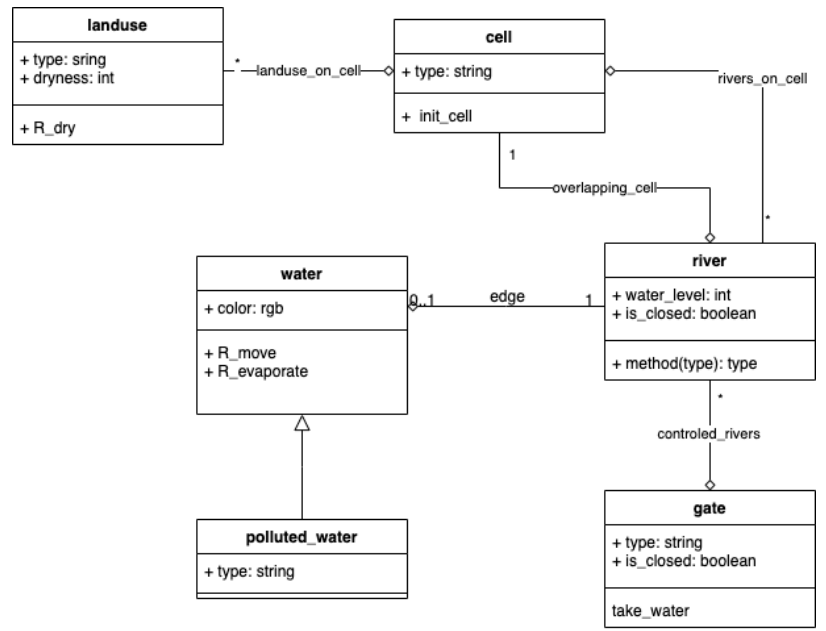

Fig. 2. Class diagram of the main entities of the model.

\section{Description of the model processes}

Within each simulation cycle, the first element to be scheduled is the water management. During this step, all the river agents' internal water level is recomputed from the water and polluted_water agents located on it. The river agents' water level is used to drive the move of the water agents: when a water has reached an intersection between rivers, it will have a higher probability to go on the river with the lowest level of water. Once each river's water level has been recomputed, the source gate agents will generate some new water agents for the water network at the location of these gates, and the sink gate agents will remove from the simulation all the water and polluted_water which arrived at those locations.

The second computing process of each cycle is the interaction between the water agents (in rivers) and the cell agents. The first processed interaction is with the clean water which may be polluted depending if the travelled landuse is already polluted. After that, the polluted_water will have the same process, but start with a chance to generate 8 static_pollution in an area of 3 kilometers around.

The third process is about the water move. In this process, the water and polluted_water agents will follow the same steps one after the other. Water agents, first, move following the river network (influenced by the water level in 
the river agents, computed at the beginning of the cycle) and, with a fixed probability, may evaporate (i.e. been remove from the simulation).

The fourth process is the disappearance of the static_pollution agents which slowly dissolve until a threshold where they are naturally removed.

Finally, each landuse agent slowly dries up with a fixed amount (set by the user).

\section{Input data}

The simulations are initialized using a set of shapefiles of the Bac Hung Hai irrigation system (summarized in Fig. 3). This dataset is composed of (i) a shapefile (of polygons) representing the shape of the four main rivers surrounding the irrigation system, used to initialize the main_river agents, (ii) a shapefile (of polylines) with the linear shape of the interior irrigation channels, used to initialize the river agents, (iii) a shapefile (of points) containing the location of the main inflow and outflow points of the system, used to initialize the eye_candy agents. For all these agents, only the geometry is read from the shapefile. As far as the gate are concerned, agents are created from a dedicated shapefile of points, and the gate type is read from the shapefile attribute table (specifying whether it is a source or a sink). All these data files have been provided by the Bac Hung Hai Irrigation System Company.

As far as the landuse agents are concerned, they are created from the opendata shapefile of the village administrative areas $^{4}$.

The overall environment of the simulations is a rectangle of $73 \mathrm{~km} \times 57 \mathrm{~km}$, corresponding to the dimensions of the shapefile used to create the main_river agents.

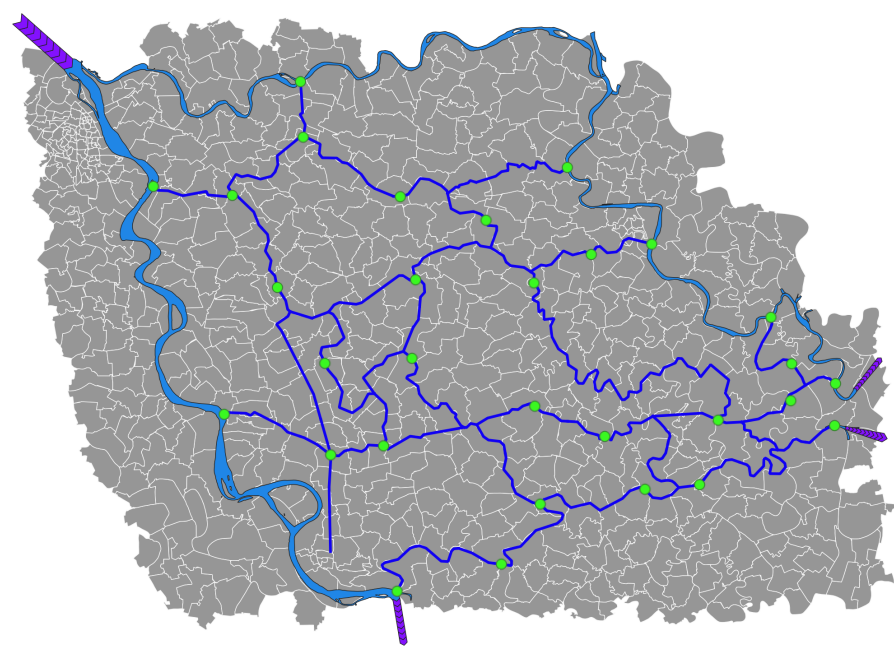

Fig. 3. Input data used to initialize the simulations: village-level administrative area (grey), in and outflow (purple), the main rivers (light blue surfaces), the main channels (dark blue lines), and gates (green disk).

Finally, the land use type of each cell comes from the Lego interactive table (described in the next section) as a JSON

\footnotetext{
${ }^{4}$ The data come from the GADM website http://gadm.org/.
}

file describing for each cell of the grid its current land use type.

\section{E. Outputs}

The display of the simulation (Fig. 4) is first made of two contextual elements (in the sense that they do not have any impact in the simulation): the surrounding rivers and the in and out flows. This allows users to recognize the area and to identify flows direction.

All the agents of the simulation are displayed, except the cell agents. Landuse agents are displayed instead as they represent a real area in the system. The idea was that the display of a grid of square cells would have appeared unrealistic to Irrigation Systems managers. In addition, it would not be coherent to display precise rivers with their real shapes while the land use only displayed on a square shape.

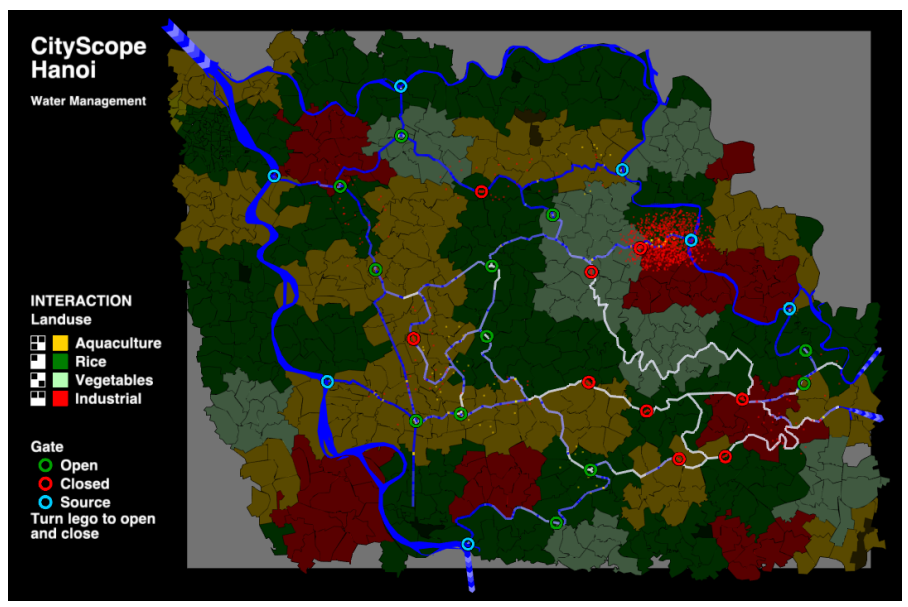

Fig. 4. Screenshot of the simulation.

Finally, a legend on the left provides information about how the land uses are represented on the map (which colour) and how they are encoded with the black and white code located behind each Lego block. This legend provides also information about the gates' colour depending on their type (source, sink, or nothing).

\section{INTERACTIVE TABLE}

The model described previously is integrated in the CityScope framework ${ }^{5}$.

\section{A. Principle of the interactive table}

The model is displayed on a table (from a ceiling-mounted projector). On this table are 64 square blocks of Lego organized as an $8 \times 8$ matrix. Figure 6 presents a picture of the table with the Lego blocks. These Lego blocks can be manipulated: they can be removed, exchanged with another Lego block or be rotated.

Each Lego block is white on the top to be used as a screen for the simulation. But on the other side, it presents a black and white code (like a minimalist QR code), that is read and

\footnotetext{
${ }^{5}$ CityScope official website: https://cityscope.media.mit.edu/.
} 

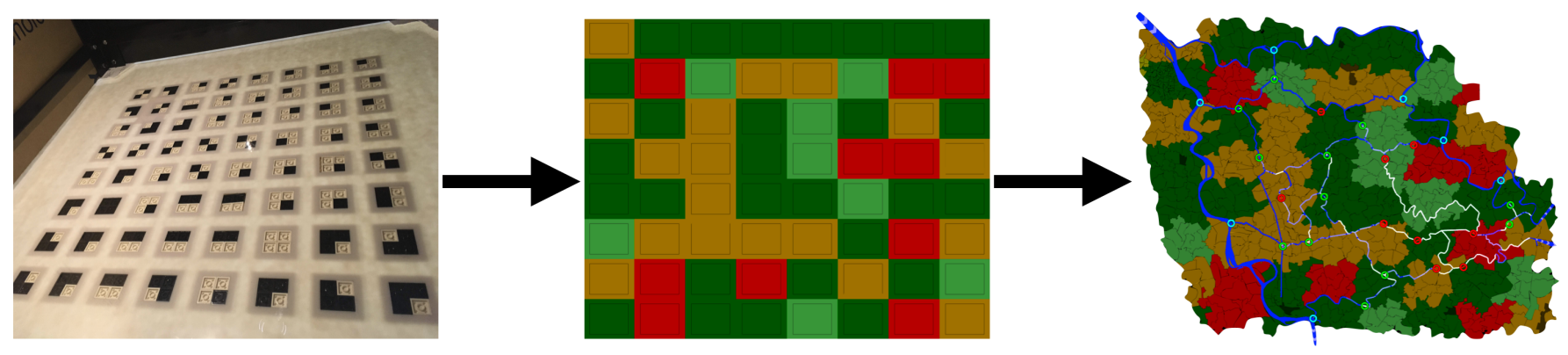

Fig. 5. Interaction principle: from Lego block to land use types.

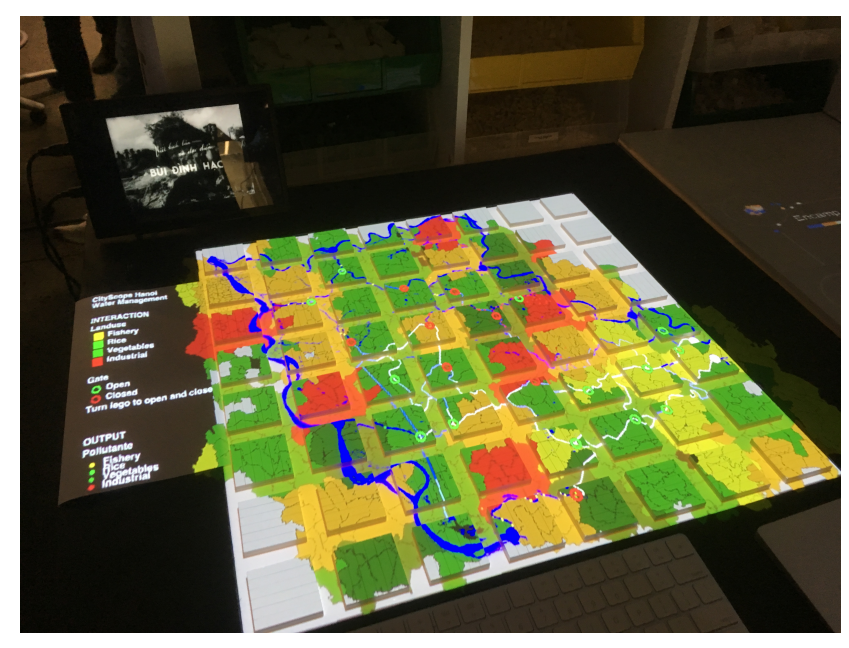

Fig. 6. Illustration of the top board of the table with the Lego blocks.

interpreted by a camera located inside the table. The CityScope framework comes with a Python scanner able to interpret this code, transform the information in a JSON file and send it to the GAMA simulation. In the simulation, a dedicated agent has been created (of species NetworkingAgent) to manage these data. When it receives the JSON file, it will parse it and assign to each cell and gate agent its new land use and closure status. Finally, the landuse agents reflect this change of land use (Fig. 5).

\section{B. Description of the hardware}

In addition to the ceiling-mounted projector connected to a computer executing the simulation, the main hardware element is the interactive table ${ }^{6}$. The table is composed of a top transparent board with a white mask plaque that has been cut to let space to Lego blocks.

In order to improve the quality of the footage taken by the camera and ensure the correctness of the code identification, the sides and bottom boards of the table are black and opaque. Inside the table are located a camera (specifications require a camera with a resolution of at least equals to 1080P), and a set of LEDs, to provide the light necessary for the camera.

\footnotetext{
${ }^{6}$ The interactive table specifications are available from the CityScope webpage https://cityscope.media.mit.edu/.
}

The camera is plugged on a computer with a specific software scanner in charge of analysis its pictures.

\section{Scanner}

The scanner is a Python open-source software ${ }^{7}$. It takes the images provided by the camera, and identifies for each Lego pixel (the size of a $1 \times 1$ Lego block) if it is black or white $^{8}$. It then aggregates the Lego pixels in blocks, each of them corresponding to 1 cell in the simulation and sends the corresponding JSON file to the dedicated agent, using the UDP communication protocol. For each cell, there are 2 data: the id number corresponding to the code, e.g. 1 could be all the blocks are black, 2 there is only 1 block white and 3 black ones (independently to position of this white block). The second information is a rotation code. For example the configuration with 1 white block and 3 black ones can appear with 4 different positions: the white block can be on the topright, top-left, bottom-right, or bottom-left location. In the 4 cases, the scanner will send the same id number, but with a different rotation number. We thus use this id number of the land use and the rotation number to set whether a gate is close or open.

\section{RESUlTS}

A first positive result of the project is that the interactive table has been presented to a wide audience during the exhibition for the 60th anniversary of Thuyloi University (Fig. 7). It has been a great opportunity to make it tested by academics, industrialists (e.g. the head of the Bac Hung Hai Irrigation Ltd, the company managing the system) and students. The feedback were really positive as people were easily able to understand what happens in the simulation, and how to interact with it. Although, the simulation appears limited for the moments in terms of possible actions to perform, this test is a first preliminary proof of correctness of the model: at least it does what it is expected to do (e.g. filling the system with industry will increase the pollution...).

Now, as far as the simulation itself is concerned, and even if we cannot calibrate it with real data in terms of hydrology,

\footnotetext{
${ }^{7}$ The scanner is available from its GitHub repository https://github.com/ CityScope/CS_CityScoPy.

${ }^{8}$ This limitation to black and white is a safety policy, the scanner could definitely recognize much more colours, but the error rate will be much higher.
} 
we can already observe some interesting patterns. In particular, source gates definitely play a key role in the simulation results: when an industry is located close to a source, it will produce much more pollution and will affect much more the system, than an industry located elsewhere.

An indirect interesting result is that, even if the previous observation can easily be understood with the rules of the model, it forces us to think whether it occurs in the real irrigation system. Improving the accuracy of the model could require more field study or interactions with experts to evaluate whether this is only a simulation artefacts or a real phenomenon.

The model thus already succeeds in raising questions and promoting interdisciplinary and cross-sectorial interactions.

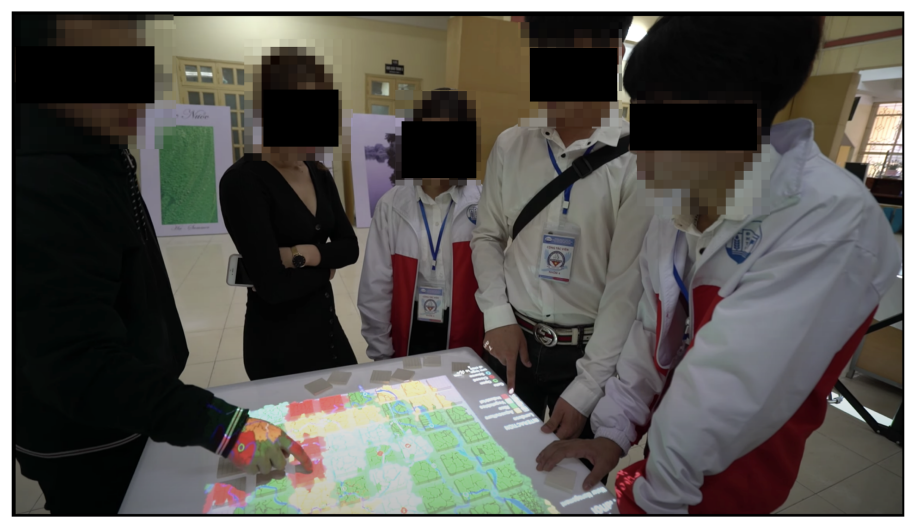

Fig. 7. Interactions and discussion around the tangible interface.

\section{CONCLUSION}

In this paper, we have presented a tangible and interactive Agent-Based Model to support decision-making and interaction around irrigation systems management alternatives and have demonstrated its interest in the path to design more sustainable solution. We also illustrate the applicability of the CityScope framework in an agriculture context. Even very promising, this model definitely needs to be improved, in particular to better take into account the link between drought and pollution.

In this model, we focused on the land use change as a way to organize and manage the space. It could be interesting to investigate now the possibilities to be more subtle (and, then, realistic) on the actions players can do on the system: as an example, players could build, repair, or destroy dykes, simply change the crop on the fields, rather than being able to change from rice to industry and back to vegetables.

\section{ACKNOWLEDGEMENT}

The CityScope project has been initiated at the MIT Media Lab. CityScope Hanoi has been funded by the CityScience group at MIT Media Lab and the JEAI WARM team, UMMISCO/Sorbonne University (SU)/IRD and Thuyloi University (TLU).

\section{REFERENCES}

[1] L. Bernstein, P. Bosch, O. Canziani, Z. Chen, R. Christ, O. Davidson, W. Hare, S. Huq, D. Karoly, V. Kattsov et al., Climate change 2007: Synthesis report: An assessment of the intergovernmental panel on climate change. IPCC, 2008.

[2] C. M. Macal and M. J. North, "Tutorial on agent-based modeling and simulation," in Proceedings of the Winter Simulation Conference, 2005. IEEE, 2005, pp. 14-pp.

[3] J.-P. Treuil, A. Drogoul, and J.-D. Zucker, Modélisation et simulation à base d'agents: exemples commentés, outils informatiques et questions théoriques. Dunod, 2008.

[4] B. Gaudou, C. Sibertin-Blanc, O. Therond, F. Amblard, Y. Auda, J.-P. Arcangeli, M. Balestrat, M.-H. Charron-Moirez, E. Gondet, Y. Hong et al., "The maelia multi-agent platform for integrated analysis of interactions between agricultural land-use and low-water management strategies," in International Workshop on Multi-Agent Systems and Agent-Based Simulation. Springer, 2013, pp. 85-100.

[5] S. Balbi, S. Bhandari, A. K. Gain, C. Giupponi et al., "Multi-agent agroeconomic simulation of irrigation water demand with climate services for climate change adaptation," Italian Journal of Agronomy, vol. 8, no. 3, p. 23, 2013.

[6] P. Taillandier, A. Grignard, N. Marilleau, D. Philippon, Q.-N. Huynh, B. Gaudou, and A. Drogoul, "Participatory modeling and simulation with the gama platform," Journal of Artificial Societies and Social Simulation, vol. 22, no. 2, 2019.

[7] C. Le Page and A. Perrotton, "Kilt: a modelling approach based on participatory agent-based simulation of stylized socio-ecosystems to stimulate social learning with local stakeholders," in International Workshop on Multi-Agent Systems and Agent-Based Simulation. Springer, 2017, pp. 156-169.

[8] P. Taillandier, B. Gaudou, A. Grignard, Q.-N. Huynh, N. Marilleau, P. Caillou, D. Philippon, and A. Drogoul, "Building, composing and experimenting complex spatial models with the GAMA platform," GeoInformatica, vol. 23, no. 2, pp. 299-322, 2019.

[9] L. Alonso, Y. R. Zhang, A. Grignard, A. Noyman, Y. Sakai, M. ElKatsha, R. Doorley, and K. Larson, "Cityscope: a data-driven interactive simulation tool for urban design. use case volpe," in International Conference on Complex Systems. Springer, 2018, pp. 253-261.

[10] V. C. Pham, G. Nguyen-Van, V. Nguyen-Thi, V. C. Le, D. NguyenNgoc, and A. Drogoul, "Modeling water flow in Bac Hung Hai Irrigation System," in Proceeding of International Symposium on Lowland Technology, 2018, pp. 1-8.

[11] A. Petrasova, B. Harmon, V. Petras, and H. Mitasova, Tangible modeling with open source GIS. Springer, 2015.

[12] T. L. Woods, S. Reed, S. Hsi, J. A. Woods, and M. R. Woods, "Pilot study using the augmented reality sandbox to teach topographic maps and surficial processes in introductory geology labs," Journal of Geoscience Education, vol. 64, no. 3, pp. 199-214, 2016.

[13] Y. Lebrun, E. Adam, R. Mandiau, and C. Kolski, "A model for managing interactions between tangible and virtual agents on an RFID interactive tabletop: case study in traffic simulation," Journal of Computer and System Sciences, vol. 81, no. 3, pp. 585-598, 2015.

[14] A. Grignard, N. Macià, L. Alonso Pastor, A. Noyman, Y. Zhang, and K. Larson, "Cityscope Andorra: a multi-level interactive and tangible agent-based visualization," in Proc. of AAMAS, 2018, pp. 1939-1940.

[15] J. Emery, N. Marilleau, N. Martiny, T. Thévenin, T. Nguyen-Huu, M. Badram, A. Grignard, H. Hbdid, A.-M. Laatabi, and S. Toubhi, "Marrakair: une simulation participative pour observer les émissions atmosphériques du trafic routier en milieu urbain," in Treizièmes Rencontres de Théo Quant, 2017.

[16] M. D. Pham, K. Chapuis, A. Drogoul, B. Gaudou, A. Grignard, N. Marilleau, and N.-H. Tri, "HoanKiemAir: simulating impacts of urban management practices on traffic and air pollution using a tangible agent-based model," in The 2020 RIVF International Conference on Computing and Communication Technologies. IEEE, 2020, pp. 1-7, to appear.

[17] V. Grimm, U. Berger, D. Deangelis, J. Polhill, J. Giske, and S. F. Railsback, "The ODD protocol: A review and first update," Ecological Modelling, vol. 221, pp. 2760-2768, 2010. 